\title{
Immune-related protein signature in serum stratify relapsed mantle cell lymphoma patients based on risk
}

Lavanya Lokhande ${ }^{1}$, Venera Kuci Emruli ${ }^{1}$, Arne Kolstad ${ }^{2}$, Martin Hutchings ${ }^{3}$, Riikka Räty ${ }^{4}$, Mats Jerkeman ${ }^{5}$ and Sara $\mathrm{Ek}^{1 *}$ (D)

\begin{abstract}
Background: Response to modern treatment strategies, which combine cytotoxic compounds with immune stimulatory agents and targeted treatment is highly variable among MCL patients. Thus, providing prognostic and predictive markers for risk adapted therapy is warranted and molecular information that can help in patient stratification is a necessity. In relapsed $\mathrm{MCL}$, biopsies are rarely available and molecular information from tumor tissue is often lacking. Today, the main tool to access risk is the MCL international prognostic index (MIPI), which does not include detailed biological information of relevance for different treatment options. To enable continuous monitoring of patients, non-invasive companion diagnostic tools are needed which can further reduce cost and patient distress and enable efficient measurements of biological markers.
\end{abstract}

Methods: We have assessed if serum-based protein profiling can identify immune related proteins that stratify relapsed MCL patients based on risk. Overall, 371 scFv targeting 158 proteins were assessed using an antibody microarray platform. We profiled patients $(n=44)$ who had been treated within the MCL6-Philemon trial combining targeted and immune-modulatory treatment.

Results: The downstream processing led to the identification of the relapsed immune signature (RIS) consisting of 11 proteins with potential to stratify patients with long and short overall survival (OS). Moreover, in this population, MIPI alone failed to separate high, intermediate and low risk patients, but a combined index based on MIPI together with RIS, MIPI ris, showed improved performance and significantly stratified all three risk groups based on OS.

\footnotetext{
* Correspondence: sara.ek@immun.Ith.se

${ }^{1}$ Department of Immunotechnology, Lund University, Lund, Sweden

Full list of author information is available at the end of the article
}

(c) The Author(s). 2020 Open Access This article is licensed under a Creative Commons Attribution 4.0 International License, which permits use, sharing, adaptation, distribution and reproduction in any medium or format, as long as you give appropriate credit to the original author(s) and the source, provide a link to the Creative Commons licence, and indicate if changes were made. The images or other third party material in this article are included in the article's Creative Commons licence, unless indicated otherwise in a credit line to the material. If material is not included in the article's Creative Commons licence and your intended use is not permitted by statutory regulation or exceeds the permitted use, you will need to obtain permission directly from the copyright holder. To view a copy of this licence, visit http://creativecommons.org/licenses/by/4.0/. The Creative Commons Public Domain Dedication waiver (http://creativecommons.org/publicdomain/zero/1.0/) applies to the data made available in this article, unless otherwise stated in a credit line to the data. 
(Continued from previous page)

Conclusions: Our results show that addition of biological parameters to previous prognostic indices improves patient stratification among patients treated with BTK inhibitor triplet combination, particularly, in the identification of an extreme high risk group.

Keywords: Mantle cell lymphoma (MCL), Serum proteins, Biomarker discovery, Protein signature

\section{Background}

An effective anti-tumor immune response plays a major role for the outcome of cancer treatment [1]. This is exemplified by the success of immuno-oncology drugs [2] and the prognostic impact of immune cells, such as Tcells and macrophages in a wide range of cancer subtypes [3, 4]. Thus, methods to assess immune profiles in patients are in high demand.

To be able to select the optimal treatment for a patient, novel efforts to use information from liquid biopsies are of major interest, as they represent a minimally invasive method that can mirror the systemic immune response to the tumor and also contain circulatory proteins and DNA secreted from the tumor itself [5]. They allow the possibility to follow the patient status over time, thus monitoring temporal variation of treatment response.

Additionally, diagnostic/prognostic tests need to be robust to be useful for their intended specific group. Unfortunately, single biomarkers often have low accuracy. Thus, the approach of utilising signatures over single biomarkers for gaining diagnostic and prognostic information, has successfully been employed in a number of studies [6-15]. The rationale is that a combination would provide far more mechanistic information, higher discriminatory power and improved biological insight [16]. Thus, the use of signatures in therapeutic decision making, development of companion diagnostic tools and personalized medicine is being explored.

In this study, we have combined three important concepts of immune focused analysis; minimally invasive sampling to evaluate if combination of proteins detected in serum can be used to risk stratify patients diagnosed with relapsed mantle cell lymphoma (MCL). The goal is to define a minimally invasive method that can help stratify patients and allow treatment selection in order to optimize outcome and reduce treatment related sideeffects.

The current golden standard in the clinic today for prognostication in MCL is the mantle cell lymphoma index, MIPI [17], which was developed for diagnostic patients and its applicability in relapsed patients is unclear. In general, the number of scientific studies focusing on relapsed MCL patients and prognostic information is limited. Few risk factors have been studied and are limited to Ki-67 and MIPI [18, 19]. The lack of tumor material from relapsed/refractory patients is a limiting factor for studies of molecular characteristics associated with relapse and refractory disease. Although it is not known how much the biology changes for the individual patient during the course of the disease, it is hypothesized that additional molecular factors can contribute to outcome. Today, when a wide range of treatment options are available in the relapsed/refractory setting, improved information on molecular features and related risk in relapsed patients is important. It is also essential that clinical tools for decision making are developed based on information gathered in homogenously treated cohorts of patients, to understand the relationship between molecular features and outcome in relapsed/refractory patients.

To identify protein signatures correlated to survival and improve patient stratification based on immune and clinicopathological parameters, we have profiled serum protein markers in a cohort of relapsed MCL patients previously collected during the Philemon trial conducted by the Nordic Lymphoma group [19]. In that trial, relapsed patients were treated with lenalidomide, rituximab and ibrutinib based on R2 induction therapy, as previously described in Ruan et al [20]. Proteins were detected using the affinity-based proteomic platform IMMray [13, 14, 21-24], which allowed us to analyze 371 proteins in serum samples collected prior to treatment initiation. Downstream analysis led to the identification of an 11 protein signature, which in combination with MIPI, robustly separate patients based on risk. The new index, referred to as MIPI $\mathrm{I}_{\text {ris }}$ (relapsed immune signature combined with MIPI) could significantly differentiate the high-risk patient subgroup and improve the overall patient stratification in this relapsed MCL patient cohort compared to either MIPI or the immune signature alone.

\section{Methods}

\section{Patient cohort}

Relapsed/refractory (R/R) MCL patient serum samples were collected from the phase two MCL6-Philemon trial (NCT02460276) (https://clinicaltrials.gov/ct2/show/ NCT02460276) conducted by the Nordic Lymphoma group. The study period was 2015-2018. Samples were collected from ten clinical sites within Sweden, Denmark, FInland and Norway. Patient eligibility criteria 
included age $>18$ years, at least one previous regimen with rituximab and measurable site of disease [19]. Patients were treated with an induction phase of 12 cycles (28 days each) with rituximab (1400 mg subcutaneously or $375 \mathrm{mg} / \mathrm{m} 2$ intravenously; once during week one and then once every eighth week), ibrutinib (orally, $560 \mathrm{mg}$ daily) and lenalidomide (orally $15 \mathrm{mg}$ per day, 1-21 in each cycle). This was followed by a maintenance phase (56 days) where the patients were given ibrutinib and rituximab only. Patients were enrolled at ten clinical sites in the Nordic countries during April 2015 and June 2016, and were followed for two years. The overall treatment response rate was evaluated using PET and CT. Overall survival (OS) was calculated as the time from study enrolment to the date of death/last follow-up; whereas progression free survival (PFS) was calculated as the time from study enrolment to date of disease progression/last follow-up/death [19]. The relapsed samples included in the study were collected at the time of enrolment in the clinical trial, prior to initiation of any treatment cycle and with a minimum of 30 days since last front-line therapy. Serum samples were stored at $-80^{\circ} \mathrm{C}$ until the day of the experiment.

\section{Labelling of serum samples}

Serum samples were biotinylated using previously optimized protocols. In brief, serum samples were first diluted (1:5 in 1XPBS) and placed on an orbital shaker at $300 \mathrm{rpm}, 4^{\circ} \mathrm{C}$ for $10 \mathrm{~min}$. The samples were then labelled with equal volume of $2.56 \mathrm{mM}$ of Biotin solution (EZ-link Sulfo-NHS-LC-Biotin (Pierce, Rockford, IL, USA)) for two hours at $4{ }^{\circ} \mathrm{C}$ on an orbital shaker. TrisHCL $(0.5 \mathrm{mM})$ was used for termination of the biotinylation reaction, for $20 \mathrm{mins}$ at $4{ }^{\circ} \mathrm{C}$ on an orbital shaker. Along the labelling process, three replicates of a reference serum sample were included as process control. The biotinylated samples were finally aliquoted and stored at $-80^{\circ} \mathrm{C}$ until further analysis.

\section{Production of human recombinant antibodies}

In total, 371 human recombinant His-tagged single chain variable fragments $(\mathrm{scFv})$ targeting 158 immunoregulatory and tumor-associated serum proteins (Supplementary Table 1), were produced and harvested in $E$. coli, and purified using MagneHis protein purification system (Promega, Madison, WI) and Zeba 96-well desalt spin plates (Thermo Fisher Scientific), according to manufacturer's protocol. Nanodrop quantification and SDS-Page was used to measure the protein yield and purity respectively.

The specificity, affinity, and on-chip functionality of the scFv's has been assured using stringent phage display selection protocols $[25,26]$, multiple clones (one to nine) per target, and a molecular design adapted for microarray application [27]. In addition, the specificity of several of the antibodies has previously been validated using well-characterized human samples and multiple orthogonal methods [22, 23, 26, 28].

\section{Detection of serum proteins using antibody microarrays}

The purified $\mathrm{scFv}$ fragments were further printed on black polymer MaxiSorp microarray slides (NUNC, Roskilde, Denmark) using a non-contact printer SciFlexarrayer S11 (Scienion, Berlin, Germany). Two columns, each containing seven identical subarrays were printed on each microarray slide. Each $\mathrm{scFv}$ analyte was printed in three replicates within each subarray (Supplementary Figure S1). BSA-biotin and PBS were used as positive and negative controls, respectively. A total of seven samples could be analyzed on one single slide.

The entire protocol has been previously optimized and standardized [13, 21, 24]. Briefly, each slide was mounted in individual hybridization gaskets. Slides were blocked for $1 \mathrm{~h}$ with constant shaking, using a blocking solution of $1 \%(\mathrm{w} / \mathrm{v})$ milk in PBST (1\% v/v Tween20 in 1XPBS) and washed with four cycles of PBST (Tween20 in 1 XPBS, $0.05 \% \mathrm{v} / \mathrm{v})$. Biotinylated serum samples, diluted 1:50 in blocking solution were then added onto the slides and incubated for $2 \mathrm{~h}$ with constant agitation, to allow the serum proteins to conjugate to their respective $\mathrm{scFv}$ fragments. Six serum samples and one quality control sample was added to each slide. The slides were again washed four times with PBST and then incubated for $1 \mathrm{~h}$ with $1 \mu \mathrm{g} / \mathrm{ml}$ of Streptavidin tagged with Alexa Fluoro 647 (Invitrogen). After the last washing step, the slides were immersed in distilled water and quickly dried with a stream of nitrogen gas and scanned immediately using Innoscan 710 (Innopsys, France) at $635 \mathrm{~nm}$.

\section{Antibody microarray data pre-processing}

To quantify spots and evaluate signal intensities, the IMMray Evaluation Software (IES, Immunovia AB, Lund, Sweden) was used. Primarily, each scanned subarray was carefully assessed for their overall quality and signal quantification. For any defects detected (background variation, uneven spots, slide scratches, spot leakage etc.) that affected any spot, the spot was removed from the downstream analysis. If $>30 \%$ of the spots in a subarray were discarded due to poor quality, the assay for that particular sample was repeated. Finally, local background was removed, and signals were extracted as an average over three replicates when the cumulative variation (CV) was below $15 \%$. If the $\mathrm{CV}$ was above $15 \%$ the outlier replicate was eliminated, and the final signal represented the average of the remaining two replicates. In addition, all mean signals were trimmed, 
meaning that $5 \%$ of the lower and upper extreme values were discarded.

For the initial analysis, the raw signals were $\log 2$ transformed and potential batch variations were assessed. Analysis and visualization was performed using three dimensional principal component analysis (PCA) with variance filtering and hierarchical clustering on Qlucore Omics Explorer (Qlucore, Lund, Sweden) and orthogonal partial least square supervised clustering on SIMCA 15 (Umetrics, Sartorius). Several technical and clinical parameters were tested for batch effect identification. Scan date (three array days) and slide batch (two slide batches printed on different days but using the same set of antibody production) were shown to cause batch effects, with scan date being the dominant factor. ComBat normalization which uses empirical Bayes framework [29] using R (Surrogate variable analysis (SVA) package, www.r-project.org) with scan date as a covariate was used to remove the batch effect.

\section{Antibody microarray data analysis}

Two parallel regression methodologies were employed to minimize false positive analytes being identified, as no validation cohort was available. In the first approach, the prognostic relevance (OS) in relation to each protein analyzed was evaluated by univariate cox regression analysis. The applicability of the cox regression model was validated by testing the independence between scaled Schoenfeld residuals with respect to time. A nonsignificant correlation for all parameters certified the validity of the proportionality hazard assumption. The list of biomarkers identified through cox regression underwent a secondary step for further variable reduction using stepwise backward elimination algorithm complemented with support vector machine and leaveone-out cross validation, using receiving operator characteristics (ROC) as the error metric. The full process, from now on referred to as Cox-BE, is described in detail in Supplementary Materials and Methods.

The second approach utilized elastic net regression (ENR) to identify key prognostic (OS) proteins. The dataset was randomly split between training (80\%) and test (20\%) groups. Multiple models were developed with varying elastic net mixing parameter $(\alpha \in[0,1]$ with increments of 0.1 ; for ridge regression $\alpha=0$ and for lasso regression $\alpha=1)$. Each model performance was estimated by the root mean square error (RMSE) and $R^{2}$ values. The model with the least RMSE and highest $R^{2}$ value was selected. Elastic net regression shrinks the coefficient to zero for redundant variables, thus, reducing the variable list providing a condensed panel of proteins associated with OS. The final signature $(n=11)$ was selected based on the overlap in proteins identified using the two separate methods. A summary of the experimental and bioinformatic pipeline is shown in Supplementary Figure S2.

\section{Analysis of condensed protein signature and development of combined risk score}

Pathway analysis (STRING: The Search Tool for the Retrieval of Interacting Genes/Proteins, (http://stringdb. org) was used to analyse the protein interaction and functional overlap between the serum proteins defining the signature. Additionally, the signature panel was used to define a protein signature score (Supplementary materials and methods S2.) based on the predicted regression coefficients from the univariate cox analysis. The signature score was determined in a way that enabled partially categorical, ternary division of the dataset $(n=44)$ (Supplementary materials and methods S2). This signature score was further used to define the new MIPI $_{\text {ris }}$ index (Supplementary materials and method S2.). To categorize the dataset into various risk groups based on the new model, cut-off points were determined by maximizing log rank statistic by minimizing the associated $p$-value. Visually, Kaplan-Meier survival curves (SPSS, SPSS Inc., Chicago, USA) were used to assess the risk stratification with respect to the OS of this patient cohort in comparison to previous prognostic indices. Harrell's concordance index and log-rank statistics were used to compare the various signatures and models. The high and low risk groups identified were further analysed using PCA and hierarchical clustering in R and Qlucore Omics explorer.

\section{Results}

\section{Patient characteristics}

Serum samples from 44 out of 50 patients were available for the present analysis and collected from seven out of ten original clinical sites. Patients characteristics for the original and present cohort is presented in Table 1 . The median follow-up time was 15 months with 18 deaths by the end of the study in 2018. The median age was 69 years with $73 \%$ of the patients above 65 years and $70 \%$ male patients. The median OS and PFS was about 15.0 and 13.7 months, respectively, similar to what has been previously reported by Owen et al, for relapsed MCL cohorts [30]. Among these 44 patients, three patients had missing information on MIPI and 12 lacked information on Ki-67. Within the MIPI distribution, $15 \%$ of the patients were low risk, 30\% intermediate risk, and 50\% high risk. More than $60 \%$ of the patients were attributed to high proliferation and Ki-67 was associated with increased risk (Table 1). 
Table 1 Patient information

\begin{tabular}{|c|c|c|c|}
\hline $\mathrm{N}(\%)$ & & Clinical trial Cohort & Present study \\
\hline Overall & & $50(100)$ & $44(100)$ \\
\hline \multirow[t]{2}{*}{ Gender } & Male & $36(72)$ & $31(70.5)$ \\
\hline & Female & $14(28)$ & $13(29.5)$ \\
\hline \multirow[t]{2}{*}{ Age at diagnosis } & $=<65$ & $15(30)$ & $14(32)$ \\
\hline & $>65$ & $35(70)$ & $30(68)$ \\
\hline \multirow[t]{4}{*}{ MIPI } & Low risk & $8(16)$ & $7(16)$ \\
\hline & Medium risk & $15(30)$ & $13(29.5)$ \\
\hline & High risk & $23(46)$ & $21(47.7)$ \\
\hline & Missing & $4(8)$ & $3(6.8)$ \\
\hline \multirow[t]{4}{*}{ TP53 } & Wild-type & $23(46)$ & $20(45.5)$ \\
\hline & Deletions & $17(34)$ & $14(31.8)^{a}$ \\
\hline & Mutated & $11(25)$ & $11(25)^{a}$ \\
\hline & Missing & $1(2.3)$ & $1(2.3)$ \\
\hline \multirow[t]{3}{*}{ Ki-67 } & $<30 \%$ & $17(34)$ & $12(27)$ \\
\hline & $>30 \%$ & $21(42)$ & $20(46)$ \\
\hline & Missing & $12(24)$ & $12(27)$ \\
\hline \multirow[t]{2}{*}{ Overall Survival (months) } & Median & 15.08 & 15.08 \\
\hline & Number of deaths & 20 & 18 \\
\hline \multirow[t]{2}{*}{ Time to progression (months) } & Median & 13.65 & 13.65 \\
\hline & Number of deaths & 24 & 21 \\
\hline Median Overall Survival (months) & & 15.08 & 15.08 \\
\hline Median Time to Progression (months) & & 13.65 & 13.65 \\
\hline
\end{tabular}

MIPI = Mantle Cell Lymphoma International Prognostic Index

${ }^{a}$ two patients had both TP53 deletion and mutation

\section{Combined regression strategy, cox-BE and ENR, to identify proteins associated with OS}

To identify proteins that were associated with OS, univariate cox regression and backward elimination (BE) were used. From the full microarray panel consisting of 371 analytes, the cox regression yielded 43 analytes with a $p$-value < 0.05 (Supplementary Fig. S3). All analytes were associated with improved outcome and had a hazard ratio $(\mathrm{HR})<1$ with a range of $0.25-0.39$ (Supplementary Fig. S3). Within this list of 43 analytes, there were 38 unique proteins, with PRD14, MCP-1, HER2/ ERBB2, Eotaxin, Keratin19 having been identified by two different scFv's.

To reduce the number of false positives, the 43 analytes underwent a second regression; stepwise backward elimination (see Materials and Methods for more detailed description). Overall, for each 12 runs of $\mathrm{BE}$, an abridged version of condensed proteins was selected based on Wilcoxon $p$-value $<0.05$ and was used for training and testing SVM leave-one-out cross-validation model. The average AUC across all runs was 0.67 with each run having an average of approximately 38 analytes.
The 23 scFv's that were identified in all 12 runs of BE were selected for further analysis (Supplementary Fig. S4). Among the 23 scFv's, two clones were directed against MCP1. For further analysis, the MCP1 scFv with the superior $\mathrm{p}$ - value was selected. Thus, the final identified enriched panel as identified by Cox-BE contained 22 proteins.

To minimize false positive analytes, a secondary approach for regression was also utilised. Elastic net regression (ENR) was chosen as it is a relevant strategy when working with small and multicollinear datasets. Several ENR models (Materials and methods) were tested using the full microarray panel of 371 analytes. The optimal $\alpha=0.5$ was chosen based on lowest RMSE = 11.50 and the highest $R^{2}=0.64$. This gave a list of 29 scFv's and their respective ENR coefficients (Supplementary Fig. S5). The identified proteins IL-4, STAP2 and Factor $\mathrm{B}$ were represented by two clones each in the analysis. For two of the proteins (STAP2 and IL-4) the coefficient provided contradictory values. Both clones that identified Factor B showed a negative correlation (ENR coefficient for clone1 $=-1.99$ and clone2 $=-0.54$ ) 


\begin{tabular}{|c|c|c|c|c|}
\hline Enriched Panel & Protein & Uniprot gene label & Uniprot used & Function \\
\hline RIS & $\mathrm{CD} 40$ & Not available & $\mathrm{Q} 6 \mathrm{P} 2 \mathrm{H} 9$ & B cell activation, Immune Response \\
\hline RIS & Eotaxin & CCL11 & P51671 & Chemokine activity \\
\hline RIS & IL-1ra & ILIRN & P18510 & Cytokine activity \\
\hline RIS & IL-4 & 144 & P05112 & Cytokine activity \\
\hline RIS & Keratin19 & KRT19 & P08727 & Cytoskeleton component \\
\hline RIS & MCP-1 & $\mathrm{CCL} 2$ & P13500 & Chemokine activity \\
\hline RIS & PRD14 & PRDM14 & Q9GZv8 & Transcription factor \\
\hline RIS & RANTES & CCL5 & P13501 & Chemokine activity \\
\hline RIS & RPSGKA2 & RPS6KA2 & Q15349 & Protein Kinase activity \\
\hline RIS & STAP2 & STAP2 & Q9иGкз & Signalling adaptor molecule \\
\hline RIS & UВС9 & UBE2I & P63279 & Adaptor signaling molecule \\
\hline COX-BE & STAT1 & STAT1 & P42224 & Protein sumoylation \\
\hline COX-BE & R-PTP-kappa & PTPRK & Q15262 & Cell adhesion and migration regulator \\
\hline COX-BE & IFN-g & IFNG & P01579 & Cytokine activity \\
\hline COX-BE & BTK & Bтк & 006187 & B cell development and activation, \\
\hline COX-BE & Itch & ITCH & Q96J02 & $\begin{array}{l}\text { immune response } \\
\text { Protein ligase }\end{array}$ \\
\hline COX-BE & CKI-epsilon & CSNK1E & P49674 & Casein kinase \\
\hline COX-BE & IL-10 & IL10 & P22301 & Cytokine activity \\
\hline COX-BE & IL-16 & IL16 & Q14005 & Cytokine activity \\
\hline COX-BE & Sox11A & sox11 & P35716 & Transcription factor \\
\hline COX-BE & AIP-3 & MAGII & 096027 & Cell adhesion and adaptor molecule \\
\hline COX-BE & PTP-1B & PTPN1 & P18031 & Protein phosphatase and UPR respons \\
\hline ENN & $A p o-A 1$ & APOA1 & P02647 & $\begin{array}{l}\text { Cholesterol binding and transfer } \\
\text { activity }\end{array}$ \\
\hline ENN & Her2/ErbB-2 & ERBB2 & P04626 & $\begin{array}{l}\text { Protein tyrosine kinase, } \\
\text { transcriotional regulator }\end{array}$ \\
\hline ENN & IL-8 & CXCL8 & P10145 & Chemokine activity \\
\hline ENN & GLP-1R & GLP1R & P43220 & $\begin{array}{l}\text { Insulin secretion regulation and } \\
\text { signalling molecule }\end{array}$ \\
\hline ENN & $\mathrm{Cla}$ & C1OA & P02745 & Complement activation \\
\hline ENN & Factor B & СғB & P00751 & Complement binding \\
\hline ENN & CDK-2 & CDK2 & P24941 & Cell cycle regulator and cell division \\
\hline ENN & GAK & GAK & Q5U4P5 & Cell cycle regulator \\
\hline ENN & PTK-6 & PTK6 & Q13882 & Cell differentiation and migration \\
\hline ENN & AGAP- 2 & AGAP2 & Q99490 & Protein kinase \\
\hline ENN & hSpindly & SPDL1 & Q96ЕА4 & Cell division \\
\hline ENN & $\operatorname{Lin}-7 \mathrm{~A}$ & LIN7A & 014910 & Vesicle exocytosis \\
\hline ENN & OTUB2 & OTUB2 & Q96DC9 & Deubiquistination of proteins \\
\hline ENN & DUSP7 & DUSP7 & 016829 & Phosphatase activity (MAPK pathway \\
\hline ENN & $\operatorname{IgM}$ & & & Immuneresponse \\
\hline
\end{tabular}

B

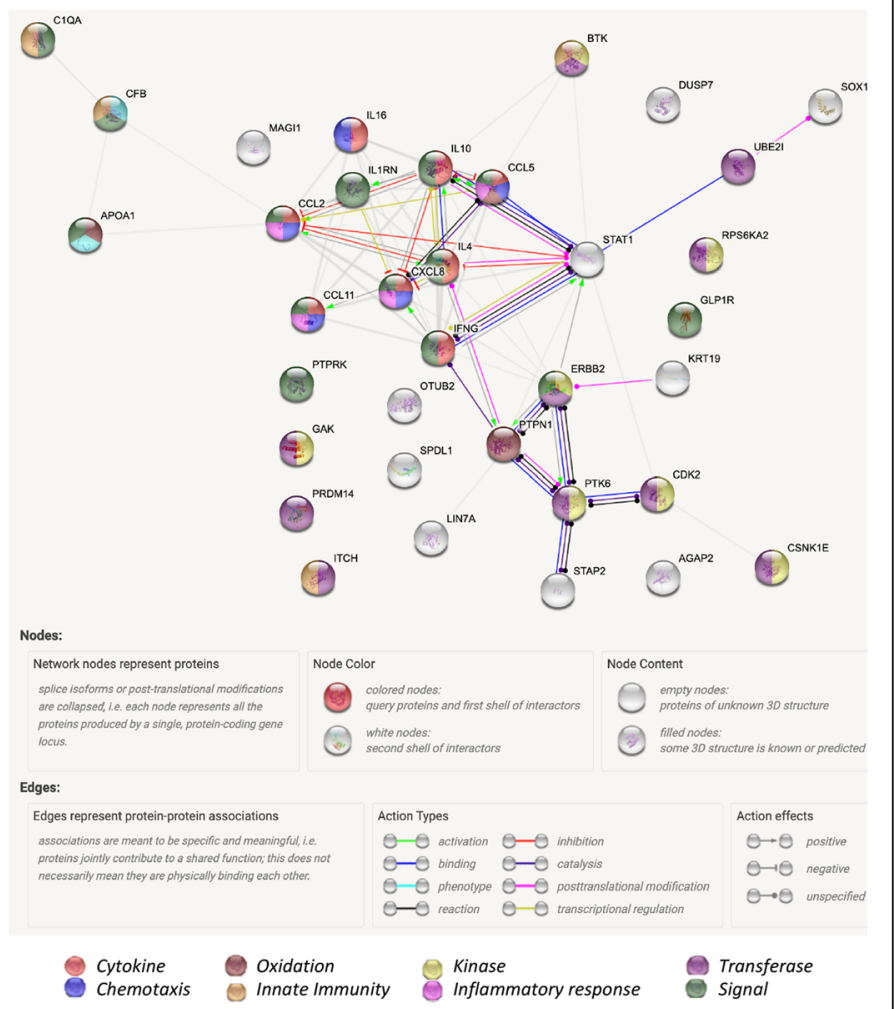

\section{C}

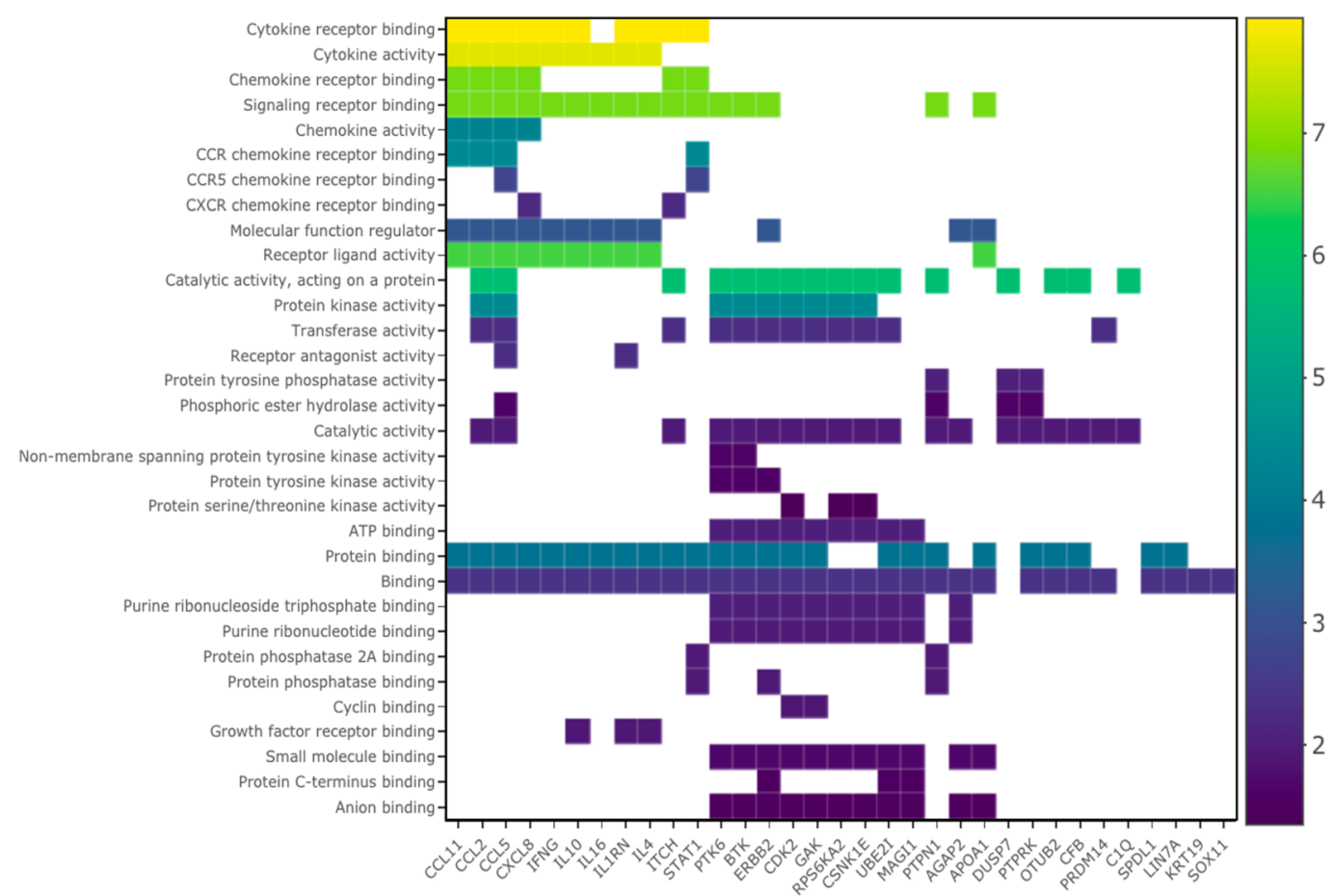

Fig. 1 Overview and network analysis of identified serum proteins. a Cumulative protein list and their corresponding Uniprot gene label, Uniprot ID used for the pathway analysis; $\mathbf{b}$ Network map of all 35 proteins listed in (a) using String; c) Overall network profile of the molecular function plotted against enrichment score (log (1/p-value)), range: 1.88-7.94 
Table 2 Univariate cox regression analysis of RIS and previously defined prognostic factors

\begin{tabular}{lllll}
\hline & $\mathbf{n}$ & $\boldsymbol{\beta}$ & HR (95\% Cl for HR) & $\mathbf{P}$ \\
\hline MIPI & 41 & 0.68 & $1.97(1.2-3.23)$ & 0.007 \\
RIS & 44 & 1.17 & $3.22(1.33-7.77)$ & 0.009 \\
KI67 & 32 & 0.02 & $1.02(1-1.05)$ & 0.03 \\
Gender & 44 & -0.12 & $0.89(0.33-2.37)$ & 0.81 \\
TP53 & 43 & 0.46 & $1.58(0.58-4.3)$ & 0.37 \\
del TP53 & 43 & -0.89 & $0.41(0.13-1.33)$ & 0.14 \\
\hline
\end{tabular}

$H R$ Hazard ratio, $\beta$ risk coefficient, $P$ p-value

in contrast to most other analytes with a positive correlation for OS. When multiple scFv's were identified or for any contradictory results, the data from Cox regression was used. The ENR approached resulted in a protein panel of 26 proteins.

\section{Functional analysis and biological implication of the enriched protein panel}

From the two enriched panels identified above by Cox$\mathrm{BE}$ and ENR, a total of 37 unique proteins were identified (Fig. 1a). To understand the multicollinearity within these 37 proteins and the possible biological interactions between them, a pathway analysis was performed. Figure 1a shows the 35 protein nodes (CD40 and IgM labels were unavailable). The results indicate that here is high degree of functional interaction between the different analytes. Of note, IL-4, IL-10, CCL2, CCL5, STAT-1 and IFN $\gamma$ have a large degree of molecular interactions. The major functional activity of the proteins include cytokine and chemokine activity (Fig. 1c).

Developing the relapsed MCL immune signature (RIS) and score based on selected proteins

The combined Cox-BE and ENR strategy identified 11 proteins that together stratify patients based on OS (Fig. 1a). Additional signature lengths were evaluated, but the overlapping signature of 11 proteins was validated to be the most significant using univariate cox analysis and Harrell's concordance index.

Table 3 Multivariate cox regression analysis to compare the significance of the RIS signature with respect to MIPI

\begin{tabular}{llllll}
\hline & & $\mathbf{n}$ & $\boldsymbol{\beta}$ & HR & $\mathbf{Q}$ \\
\hline A & MIPI & 41 & 0.708 & $2.03(1.24-3.33)$ & 0.009 \\
& RIS & 41 & 1.327 & $3.77(1.38-10.3)$ & 0.009 \\
\multirow{2}{*}{ B } & MIPI & 30 & 0.778 & $2.18(1.23-3.85)$ & 0.023 \\
& RIS & 30 & 1.201 & $3.32(1.18-9.34)$ & 0.034 \\
& Ki-67 & 30 & 0.017 & $1.02(0.998-1.04)$ & 0.081 \\
\hline \multicolumn{7}{l}{ HR Hazard ratio, $\beta$ risk coefficient, Q q-value (FDR corrected p-value) } \\
\end{tabular}

HR Hazard ratio, $\beta$ risk coefficient, $Q \mathrm{q}$-value (FDR corrected $\mathrm{p}$-value)
For evaluating the efficacy of the signature in risk stratification, these 11 identified proteins were used to develop a relapsed MCL immune signature score (RIS score) as described in the Supplementary Materials and Methods. Univariate cox regression (OS, Table 2) was used to compare the efficacy of the RIS score to MIPI, Ki-67 (\%), TP53 mutational status or TP53 deletion. It was shown that MIPI, RIS and Ki-67 were identified as significant factors associated with OS in this patient cohort (Table 2). However, the HR for Ki-67 barely reached significance at $1.023(95 \% \mathrm{CI}=1-1.05, P<0.05)$, probably due to limited number of patients. In comparison to MIPI with a HR of 1.97 (95\% CI $=1.2-3.23, \mathrm{P}<$ $0.05)$, RIS exhibited a 3.2 fold increase $(95 \% \mathrm{CI}=1.33-$ $7.77, P<0.01)$, highlighting the strong association of the RIS score with OS. Gender was non-significant in both univariate and multivariate model and thus no impact on the significant variables mentioned above. Of note, univariate analysis of TP53 mutation or deletion to OS was not significant in this patients cohort (Table 2) as reported previously [19], most likely due to the noncytotoxic regiment used in the clinical trial protocol.

\section{Comparison of the RIS to previous prognostic indices and development of the combined $\mathrm{MCL}$ relapsed immune signature index $\left(\mathrm{MIPI}_{\text {ris }}\right)$}

To evaluate the impact of the developed immune-related score, RIS, together with MIPI, multivariate cox regression analysis was performed. The HR and $\beta$ for RIS was 3.77 and 1.327 respectively $(q<0.01)$, nearly twice the impact compared to MIPI with $\mathrm{HR}=2.03$ and $\beta=0.708$ $(\mathrm{q}<0.01)$ (Table 3$)$. Proliferation lost prognostic relevance in a multivariate model together with MIPI and RIS (Table 3), which may be related to that information on proliferation only was available for 30 patients which reduce statistical power. We additionally checked the performance of TP53 mutation/deletion against MIPI and RIS in a multivariate analysis. However, it was nonsignificant and did not contribute towards the hazard risk. To evaluate the efficacy of a combined index taking both biological and patient-related parameters into account, we combined information from the 11 proteins constituting the RIS with the MIPI. The MIPI ${ }_{\text {ris }}$ was calculated as weighted sum of the MIPI and RIS and the weights were defined by the risk coefficients from the multivariate analysis (Supplementary Material and Methods). The new index was defined as: MIPI $_{\text {ris }}=$ [0.708 X MIPI $]+[1.327$ X S11]

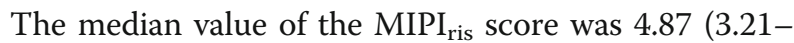
7.35). To trichotomize the data, potential cut-offs were evaluated by testing several iterations and final optimal boundary conditions were determined as 3.97 and 5.62 based on optimizing log-rank statistic and using minimal $p$-value approach $\left(\mathrm{X}^{2}=12.883, P=0.0016\right)$. Thus, the 


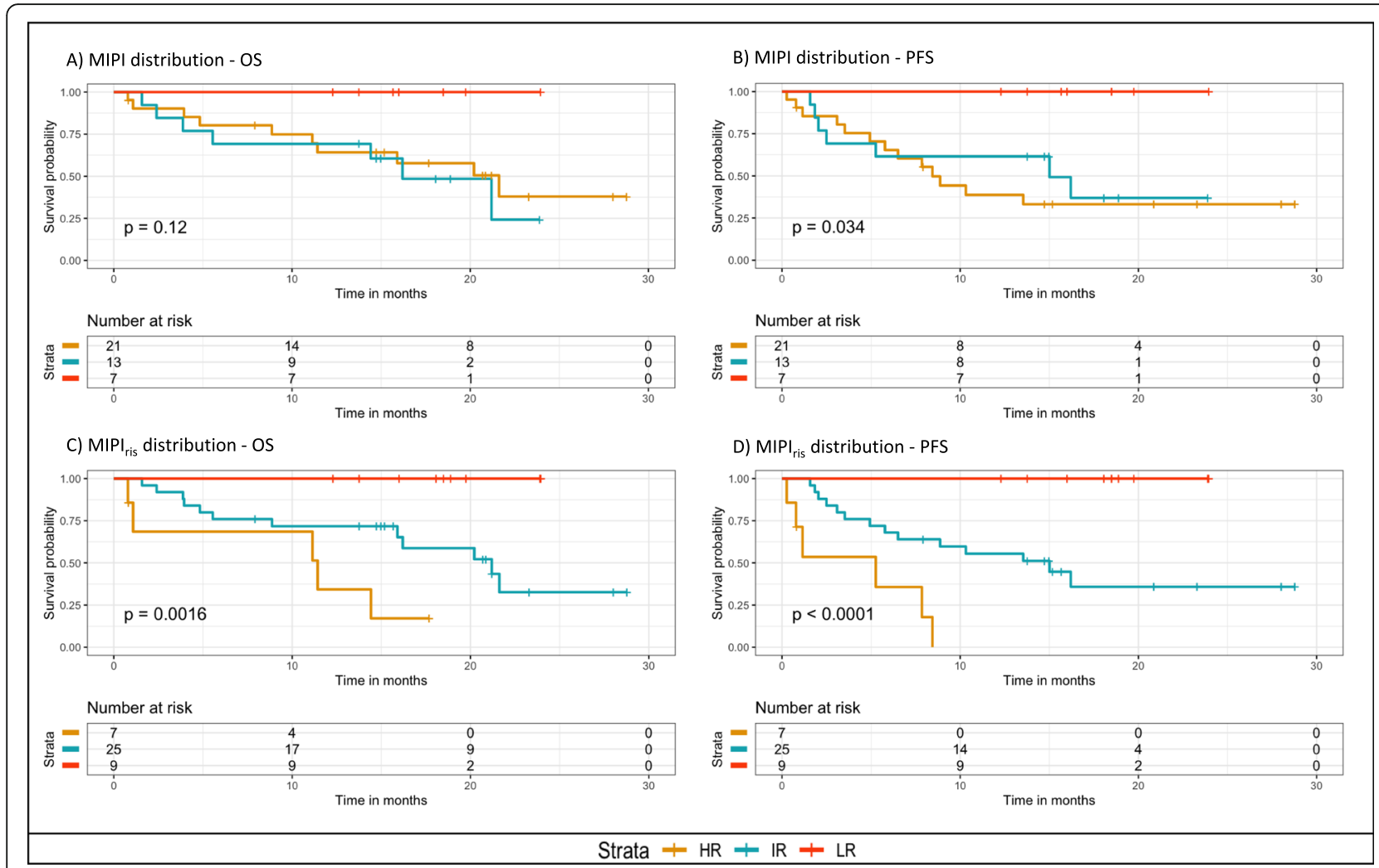

Fig. 2 Kaplan Meier estimator comparing how MIPI and MIPI ris stratify patients according to outcome. $\mathbf{a}$ and $\mathbf{b}$ are MIPI risk distribution (LR $\leq 5.7$; $5.7<\operatorname{IR}<6.2 ; 6.2 \leq \mathrm{HR}$ ) with respect to overall survival and progression free survival respectively; $\mathbf{c}$ and $\mathbf{d}$ are $\mathrm{MIPI}_{\text {ris }}$ risk distribution (LR $\leq 3.97$; $3.97<\mathbb{R}<5.62 ; 5.62 \leq \mathrm{HR}$ ) with respect to overall survival and progression free survival respectively. $L R=$ low risk, $I R=$ intermediate risk, $\mathrm{HR}=$ high risk

dataset was stratified in three subgroups as the following; low risk $(\mathrm{LR}) \leq 3.97,3.97<$ intermediate risk $(\mathrm{IR})<$ 5.62, $5.62 \leq$ high risk (HR). The final patient distribution was nine patients $(22 \%)$ in the low risk group, 29 patients $(61 \%)$ in the intermediate risk group and six patients $(17 \%)$ in the high risk group.

MIPI alone failed to significantly divide the relapsed patients into distinct risk groups (log-rank statistic $=$ $4.279, \mathrm{df}=2, p=0.118$ ), with the survival curves for high and the intermediate risk groups being undifferentiated and only low risk group separated (Fig. 2a). The patients were distributed over the different risk groups with $51.1 \%$ patients $(n=21)$ in the high risk group, $31.70 \%$ $(n=13)$ in the intermediate risk group and $17.01 \%(n=$ 7 ) in the low-risk group. In contrast, the combined MIPI $_{\text {ris }}$, could clearly and significantly differentiate between the three subgroups with a log-rank $p$-value of 0.0016 (Fig. 2c). Also for progression free survival (PFS), the MIPI $\mathrm{I}_{\text {ris }}$ had a stronger prognostic impact compared to MIPI alone $(p<0.0001$ and $p=0.034$, respectively). MIPI $_{\text {ris }}$ could clearly separate the three risk groups with the survival curves for high and the intermediate risk groups clearly separated (Fig. 2c and d). Harrell's concordance index performance was slightly better for MIPI $_{\text {ris }}(0.714)$ compared to MIPI alone (0.662). Out of the seven patients in the low-risk MIPI group, six remained in the low-risk MIPI ${ }_{\text {ris }}$ group.

The overall risk distribution was visualized by PCA as shown in Fig. 3a, again exhibiting the segregation of high and low risk groups of the MIPI ${ }_{\text {ris }}$ by differential confidence clusters. The separation was primarily along the first component axis, likely explained by the overlapping functions of the individual RIS proteins as demonstrated by the pathway analysis. The expression of the 11 proteins in the defined RIS were increased in the low risk group compared to the high risk group (Fig. 3b).

\section{Discussion}

Risk stratification is important for clinical practice, and the golden standard today is MIPI which was developed in 2008 for assessment of risk in newly diagnosed patients. The index is based on four parameters; age, LDH levels, WBC count and ECOG status [17]. However, MIPI does not take the biological heterogeneity into account, as limited molecular data is included [31]. Moreover, later studies where more modern treatment 
A
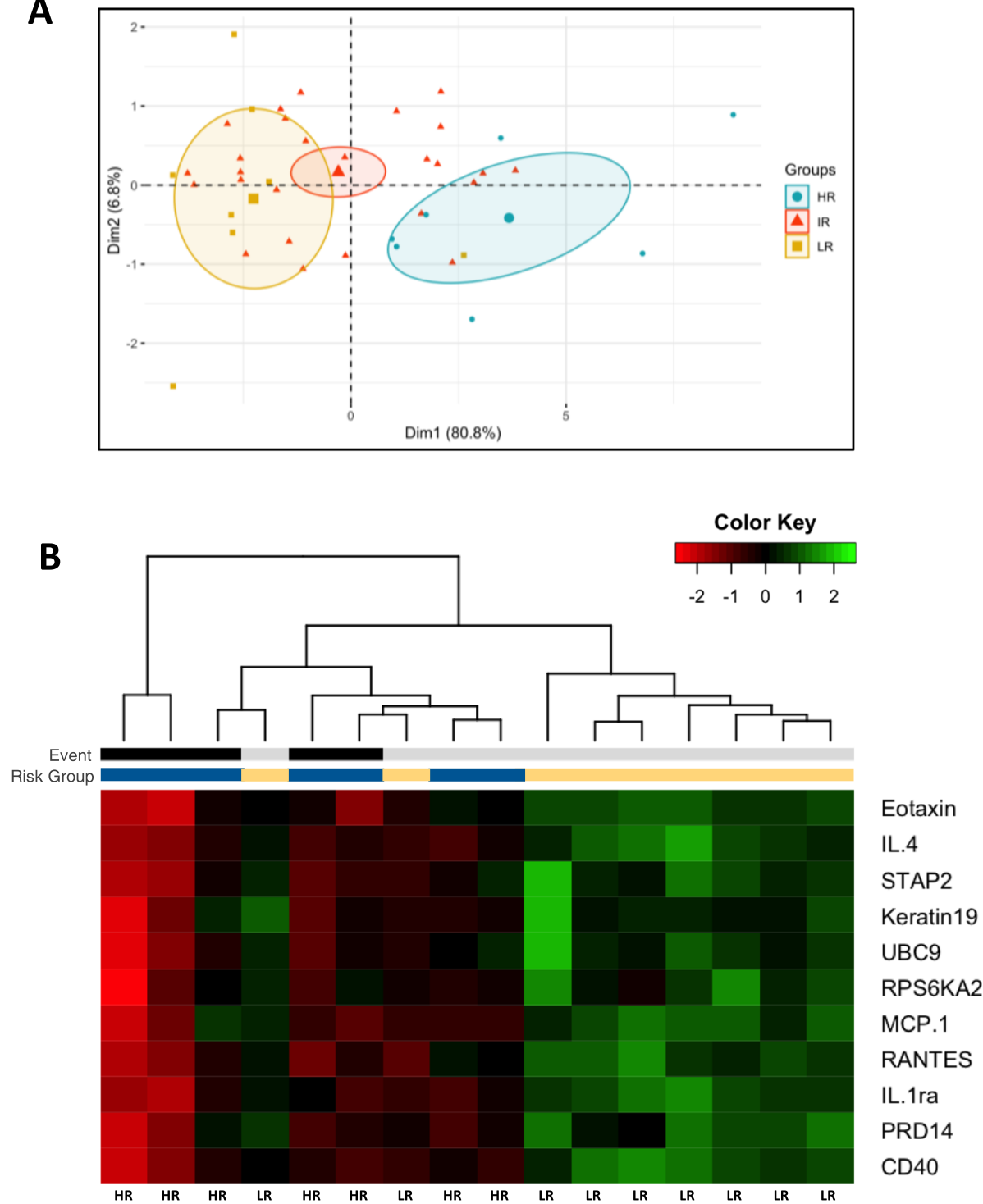

Fig. $3 \mathrm{MIPI}_{\text {ris }}$ risk distribution and variation within groups, highlighting high risk groups. a PCA risk distribution particularly differentiating high and low risk group, the ellipses represent the confidence of the distribution per risk category; $\mathbf{b}$ hierarchical clustering of the 11 antigens part of the relapsed MCL immune signature and MIPI ris; number of events (black: death, grey: live) and risk group (blue: high risk, yellow: low risk) is provided in the legend above

regimens are used, have shown that the index does not differentiate between low, intermediate and high risk groups of patients [32-35]. When combined with additional molecular information specific to individual patients, combined indices have improved risk stratification [31, 36-39]. The most widely used combined index is the MIPI-b where proliferation based on Ki-67 staining is added to the original MIPI [37]. Apart from this, there are several other prognostic factors and single markers identified in MCL such as the neural transcription factor SOX11 [40] and several secondary mutations (TP53, MYC, ATM, NOTCH1 etc.) [40]; among which TP53 mutational status has shown largest impact on outcome [41]. However, there are limited studies on how soluble immune-related proteins in serum can contribute to assessment of risk, and stratification of MCL patients. To our knowledge, only a single study by Sonbol et al. has focused on cytokines in MCL blood samples [42], where sIL-2R $\alpha$, MIP-1 $\beta$ and IL-8 were identified as prognostic factors.

Thus, we have assessed the potential of using information in serum to associate combinations of proteins with response of relapsed MCL patients to treatment with immune-stimulatory agents. The identified signature, RIS, includes PRD14, STAP2, Eotaxin, RPS6KA2, Keratin19, MCP1, IL4, UBC9, IL1ra, RANTES and CD40. 
Most of the proteins have a known role in the immune system, but the majority have not been studied in the context of MCL biology or treatment response. Sonbol et al., identified IL1ra levels to be elevated in relapsed MCL in comparison to healthy controls, but was not correlated to event-free survival in that study [42]. Few of the RIS proteins have been studied in MCL tumor tissue, and thus we cannot speculate if the protein is leaking from the tumour cells, or altered as a response by the immune system to the tumor. However, RANTES (CCL5) has been reported to be overexpressed in MCL tumor tissue and MCL cell lines, tentatively playing a role in recruitment of $\mathrm{T}$ cells [43].

Several of the other proteins are well characterized in relation to their role in the immune system. IL-4 is a central hub for regulating immune behaviour and has previously been attributed to cell proliferation through the impact on CD40L [44]. CD40, a member of TNF receptor family plays an essential role in B cell proliferation, although it's role in MCL has been under dispute [45-47]. While some studies suggest the involvement of CD40 in promoting MCL tumor cell proliferation, others debate the potential role in growth arrest $[45,47]$.

Of interest, the transcription factor PR domain zinc finger 14 (PRD14 or PRDM14), a regulator of pluripotency and epigenetic reprogramming in embryonic stem cells and germ cells [48-50], has not been studied in MCL, but other reports link high PRD14 to oncogenic behaviour in several cancer types including breast cancer and colorectal cancer [51-56]. It has been proposed that PRDM14 (corresponding gene) expression could influence G1/S transition thus enabling cell proliferation [49] and facilitate cancer stem cell like properties and chemoresistance. Thus, inhibition of PRDM14 has also been suggested as a potential target of treatment in cancer therapy [53]. Importantly, it has been shown that PRDM14 overexpression leads to lymphoma formation in mice [57]. One of the other family members, PRDM1, is a master regulator of B-cell differentiation and acts as a tumor suppressor in DLBCL [58-60]. Potentially, it would be interesting to study PRDM14 in MCL tissue to understand if it is expressed by the tumor cells or secreted by the immune system.

The first aim of the present study was to identify a signature that could stratify patients according to risk. This was assessed by calculating a patient-specific score based on the individual intensities weighted by their contribution in a combined multivariate analysis. The patient's RIS score could then be used to stratify patients according to risk (OS). Additionally, we also evaluated the prognostic value of established risk factors, including proliferation and MIPI together with the RIS score. Both Ki-67 and MIPI were independently associated with OS in cox multivariate analysis together with RIS. However, RIS had a stronger impact with an increased HR of 3.3 as compared to 2.1 for MIPI and 1.02 for Ki-67. As reported previously, TP53 aberrations were not correlated to OS in univariate analysis [19], potentially related to the fact that a non-chemotherapeutic regimen was used that do not depend on functional p53.

The second aim was to evaluate if risk stratification could further be improved by combining information from the RIS score with the clinically used MIPI. We show that MIPI alone does not significantly stratify these relapsed patients into distinct high, intermediate and low risk groups. When combining RIS and MIPI scores, and using optimized cut-offs, improved stratification was achieved. We show that MIPI ris can improve separation between low, intermediate and high risk patients compared to MIPI alone, emphasizing that non-invasive sampling of immune-related serum proteins can be used to improve risk stratification in relapsed/refractory MCL patients. This newly defined index had a stronger impact than MIPI and MIPI-b in stratification using cox analysis, KM survival curves, log-rank statistics and Harrell's concordance index.

Already today in the clinic, risk adapted therapy regimens based on MIPI are being explored [31]. In the diagnostic setting, low MIPI score patients are considered for wait-and-watch strategy whereas the intermediate or high risk group are proposed to be treated with combination chemotherapy (CHOP) and immune therapy (Rituximab), dosage depending on additional prognostic factors such as TP53, Ki-67 etc. [61]. Thus, improving stratification through addition of biological information can potentially enable better decision making for treatment regimens in both the diagnostic and relapsed setting.

The potential of including information on immunerelated proteins is increasingly important for novel treatment strategies that often include immune stimulatory agents or strategies in both the diagnostic and relapsed setting. Most likely, the RIS protein panel is related to the specific treatment that the patients received, and the global applicability of such specific panels needs to be investigated in cohorts of patients receiving other treatment protocols.

\section{Conclusion}

In this proof-of concept study, we have used three important concepts to risk-stratify patients, and enable improved clinical decision making through (i) minimally-invasive patient sampling, (ii) combined protein signature in contrast to single biomarkers and (iii) focus on immune-related information relevant to treatment outcome. We show that information from immune-related proteins in serum can be used alone or 
in combination with clinical parameters to improve stratification of patients treated with immunestimulatory and targeted agents.

\section{Supplementary Information}

The online version contains supplementary material available at https://doi. org/10.1186/s12885-020-07678-4.

Additional file 1 Supplementary Table 1. Antibody clones used in the microarray platform targeting a total of 158 unique antigens.

Additional file 2 Supplementary Figure S1. Example of an scanned array slide. The figure is an example of one scanned subarray slide, containing approximately $\sim 190$ different antibodies (half of the entire microarray set) printed as spots in triplicates. Each replicate set is bordered with the positive control (BSA-Biotin) and PBS was used as negative control.

Additional file $\mathbf{3}$ Supplementary Figure S2. An overview of the experimental and bioinformatic pipeline.

Additional file 4 Supplementary Figure S3. List of 43 analytes associated with overall survival based on univariate cox regression ordered as per their $p$-value significance. Black dots: Hazard ratio (HR) or exp.( $\beta$ ) where $\beta$ is the risk coefficient, orange dots: $95 \%$ lower HR limit, blue dots: $95 \%$ higher HR limit. * Represents the marker identified by multiple scFv clones and the arrow marks indicate the duplicate clones; P: p-value.

Additional file $\mathbf{5}$ Supplementary Figure S4. Backward elimination coupled with SVM and LOOCV post cox regression. A) Boxplot of the ROC-AUC values across all 12 iterations of BE; and B) the frequency of appearance of each 43 analyte as identified previously by cox regression. In total, 23 analytes for 22 unique serum proteins (MCP1 identified by 2 scFv's) were identified in all 12/12 iterations (as highlighted by the red box) which were selected as the enriched panel for Cox-BE.

Additional file $\mathbf{6}$ Supplementary Figure S5. Illustration of the second regression approach using elastic net regression (ENR). The entire microarray panel of 371 analytes were used. A) error graph for the log (lambda) values. B) Coefficient collapse to zero for $a=0.5$, wherein only 29 analytes were eventually selected with non-zero coefficients. C) The regressed panel of 29 parameters plotted against the ENR coefficients. Coefficient < 0 ("Negative") implies negative correlation to OS; Coefficient > 0 ("Positive") implies positive correlation to OS.

Additional file 7. Supplementary materials and methods.

\section{Abbreviations}

MCL: Mantle Cell Lymphoma; OS: Overall Survival; PFS: Progression Free Survival; MIPI: Mantle cell lymphoma International Prognostic Index;

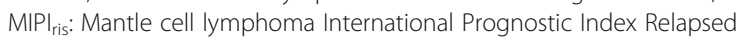
Immune Signature; RIS: Relapsed Immune Signature

\section{Acknowledgments}

We want to acknowledge the technical help from Corinna Richter and Lisa Theorin with antibody production and slide production. We want to acknowledge Immunovia AB for antibody printing assistance.

\section{Authors' contributions}

Study design: SE, VKE and LL; Data collection: LL, AK, MH, RR, MJ; Data analysis: LL and VKE; Manuscript preparation: LL and SE. The authors read and approved the final manuscript.

\section{Funding}

The project was partly funded through research grants sought in open competition for the specific project. Thus, the funding agencies had no part in designing the project or interpretation of the data. The European Community's Horizon 2020 Framework Programme for Research and Innovation (EU-H2020-MSCA-COFUND-2016-754299) partly funded the salary of the participating doctoral student. Cancerfonden 2016/465, Cancerfonden 2019/0309, Mats Paulssons stiftelse för Forskning, innovation och samhallsbyggande, Stefan Paulssons cancerfond and Fru Berta Kamprad
FBKS-2018-7-(149) covered part of doctoral student salary and reagents cost for the IMMRay experiments. Open Access funding provided by Lund University.

\section{Availability of data and materials}

The datasets used and/or analysed during the current study are available from the corresponding author on reasonable request. Supplementary figures (1, 2, 3, 4 and 5) and Table 1, as well as supplementary materials and methods are provided.

\section{Ethics approval and consent to participate}

The study was approved according to national and international law by the regional ethic committee at Lund University (Lund regional ethic committee, Dnr 2014-709), and included written informed consent for all participants.

\section{Consent for publication}

Not applicable.

\section{Competing interests}

The authors declare that they have no competing interests.

\section{Author details}

${ }^{1}$ Department of Immunotechnology, Lund University, Lund, Sweden. ${ }^{2}$ Oslo University Hospital, Oslo, Norway. ${ }^{3}$ Department of Haematology, Rigshospitalet, Copenhagen, Denmark. ${ }^{4}$ Department of Hematology, Helsinki University Central Hospital, Helsinki, Finland. ${ }^{5}$ Department of Oncology, Lund University, Lund, Sweden.

Received: 17 September 2020 Accepted: 22 November 2020

Published online: 07 December 2020

\section{References}

1. Antonia SJ, Larkin J, Ascierto PA. Immuno-oncology combinations: a review of clinical experience and future prospects. Clin Cancer Res. 2014;20:625868. https://doi.org/10.1158/1078-0432.CCR-14-1457.

2. Ben-Aharon $\mathrm{O}$, Magnezi R, Leshno M, Goldstein DA. Association of immunotherapy with durable survival as defined by value frameworks for cancer care. JAMA Oncology. 2018;4:326-32.

3. Gun SY, Lee SWL, Sieow JL, Wong SC. Targeting immune cells for cancer therapy. Redox Biol. 2019;25:101174.

4. Munhoz RR, Postow MA. Recent advances in understanding antitumor immunity. F1000 Res. 2016;5:2545.

5. De Rubis G, Rajeev Krishnan S, Bebawy M. Liquid biopsies in Cancer diagnosis, monitoring, and prognosis. Trends Pharmacol Sci. 2019;40(3):17286.

6. Liu X, Zheng W, Wang W, Shen H, Liu L, Lou W, et al. A new panel of pancreatic cancer biomarkers discovered using a mass spectrometry-based pipeline. Br J Cancer. 2017;117:1846-54.

7. Geary B, Walker MJ, Snow JT, H Lee DC, Pernemalm M, Maleki-Dizaji S, et al. Identification of a biomarker panel for early detection of lung Cancer patients. J Proteome Res. 2019;18:3369-82. https://doi.org/10.1021/acs. jproteome.9b00287.

8. Chung L, Moore K, Phillips L, Boyle FM, Marsh DJ, Baxter RC. Novel serum protein biomarker panel revealed by mass spectrometry and its prognostic value in breast cancer. Breast Cancer Res. 2014;16:1-12.

9. Wingren C, Sandstr $€$ Om A, Segersv€ Ard R, Carlsson A, Andersson R, L€ Ohr $\mathrm{M}$, et al. Identification of Serum Biomarker Signatures Associated with Pancreatic Cancer. Cancer Res. 2012;72:2481-90. https://doi.org/10.1158/ 0008-5472.CAN-11-2883.

10. Enroth S, Berggrund M, Lycke M, Broberg J, Lundberg M, Assarsson E, et al. High throughput proteomics identifies a high-accuracy 11 plasma protein biomarker signature for ovarian cancer. Commun Biol. 2019;2:1-12.

11. Shen Q, Polom K, Williams C, de Oliveira FMS, Guergova-Kuras M, Lisacek F, et al. A targeted proteomics approach reveals a serum protein signature as diagnostic biomarker for resectable gastric cancer. EBioMedicine. 2019;44: 322-33. https://doi.org/10.1016/j.ebiom.2019.05.044.

12. Andrew John Li M. What's new in biomarker testing for ovarian cancer. Contemporary OB/GYN. 2019;64:26-8.

13. Mellby LD, Nyberg AP, Johansen JS, Wingren C, Nordestgaard BG, Bojesen $\mathrm{SE}$, et al. Serum biomarker signature-based liquid biopsy for diagnosis of 
early-stage pancreatic Cancer. J Clin Oncol. 2018;36:2887-94. https://doi.org/ 10.1200/JCO.2017.77.6658.

14. Sandström A, Andersson R, Segersvärd R, Löhr M, Borrebaeck CAK, Wingren C. Serum proteome profiling of pancreatitis using recombinant antibody microarrays reveals disease-associated biomarker signatures. Proteomics Clin Appl. 2012;6:486-96.

15. Boylan KLM, Geschwind K, Koopmeiners JS, Geller MA, Starr TK, Skubitz APN. A multiplex platform for the identification of ovarian cancer biomarkers. Clin Proteomics. 2017;14:34

16. CA KB. Precision diagnostics: moving towards protein biomarker signatures of clinical utility in cancer; 2017. https://doi.org/10.1038/nrc.2016.153.

17. Hoster E, Dreyling M, Klapper W, Gisselbrecht C, van Hoof A, Kluin-Nelemans $\mathrm{HC}$, et al. A new prognostic index (MIPI) for patients with advanced-stage mantle cell lymphoma. Blood. 2008;111:558-65. https://doi.org/10.1182/ blood-2007-06-095331.

18. Goy A, Kalayoglu Besisik S, Drach J, Ramchandren R, Robertson MJ, Avivi I, et al. Longer-term follow-up and outcome by tumour cell proliferation rate (Ki-67) in patients with relapsed/refractory mantle cell lymphoma treated with lenalidomide on MCL-001(EMERGE) pivotal trial. Br J Haematol. 2015; 170:496-503.

19. Jerkeman M, Eskelund CW, Hutchings M, Räty R, Wader KF, Laurell A, et al. Ibrutinib, lenalidomide, and rituximab in relapsed or refractory mantle cell Iymphoma (PHILEMON): a multicentre, open-label, single-arm, phase 2 trial. Lancet Haematol. 2018;5:e109-16. https://doi.org/10.1016/S23523026(18)30018-8.

20. Ruan J, Martin P, Shah B, Schuster SJ, Smith SM, Furman RR, et al. Lenalidomide plus rituximab as initial treatment for mantle-cell lymphoma. N Engl J Med. 2015;373:1835-44. https://doi.org/10.1056/NEJMoa1505237.

21. Delfani $P$, Dexlin Mellby L, Nordström M, Holmér A, Ohlsson M, Borrebaeck CAK, et al. Technical advances of the recombinant antibody microarray technology platform for clinical Immunoproteomics. PLoS One. 2016;11: e0159138. https://doi.org/10.1371/journal.pone.0159138.

22. Carlsson A, Wingren C, Kristensson M, Rose C, Fernö M, Olsson H, et al. Molecular serum portraits in patients with primary breast cancer predict the development of distant metastases. Proc Natl Acad Sci U S A. 2011;108:14252-7.

23. Ingvarsson J, Wingren C, Carlsson A, Ellmark P, Wahren B, Engström G, et al. Detection of pancreatic cancer using antibody microarray-based serum protein profiling. PROTEOMICS. 2008:8:2211-9. https://doi.org/10.1002/pmic. 200701167.

24. Carlsson A, Wuttge DM, Ingvarsson J, Bengtsson AA, Sturfelt G, Borrebaeck CAK, et al. Serum protein profiling of systemic lupus erythematosus and systemic sclerosis using recombinant antibody microarrays. Mol Cell Proteomics. 2011;10

25. Söderlind E, Strandberg L, Jirholt P, Kobayashi N, Alexeiva V, Åberg AM, et al. Recombining germline-derived CDR sequences for creating diverse single-framework antibody libraries. Nat Biotechnol. 2000;18:852-6.

26. Säll A, Walle M, Wingren C, Müller S, Nyman T, Vala A, et al. Generation and analyses of human synthetic antibody libraries and their application for protein microarrays. Protein Eng Des Sel. 2016;29:427-37.

27. Borrebaeck CAK, Wingren C. Recombinant antibodies for the generation of antibody arrays. Methods Mol Biol. 2011;785:247-62.

28. Ingvarsson J, Larsson A, Sjöholm AG, Truedsson L, Jansson B, Borrebaeck CAK, et al. Design of recombinant antibody microarrays for serum protein profiling: targeting of complement proteins. J Proteome Res. 2007;6:3527-36.

29. Johnson WE, Li C, Rabinovic A. Adjusting batch effects in microarray expression data using empirical Bayes methods. Biostatistics. 2007;8:118-27. https://doi.org/10.1093/biostatistics/kxj037.

30. Owen C, Berinstein NL, Christofides A, Sehn LH. Review of bruton tyrosine kinase inhibitors for the treatment of relapsed or refractory mantle cell Iymphoma. Curr Oncol. 2019;26:e233-40.

31. Liebers N, Dreger P, Dreyling M, Dietrich S. Risk stratification of mantle cell lymphoma (MCL). Ann Lymphoma. 2018;2:10.

32. Eve HE, Gambell J, Smith P, Qian W, Rule SAJ. The simplified mantle cell lymphoma international prognostic index predicts overall survival but not progression-free survival in patients with mantle cell lymphoma treated with fludarabine and cyclophosphamide \pm rituximab: results of a randomized phase II trial. Leuk Lymphoma. 2009;50:1709-11. https://doi.org/10.1080/ 10428190903186494

33. Schaffel R, Hedvat CV, Teruya-Feldstein J, Persky D, Maragulia J, Lin D, et al. Prognostic impact of proliferative index determined by quantitative image analysis and the International Prognostic Index in patients with mantle cell lymphoma. Ann Oncol. 2010:133-9 https://www.ncbi.nlm.nih.gov/pmc/ articles/PMC2795614/. Accessed 26 Apr 2020.

34. Geisler CH, Kolstad A, Laurell A, Jerkeman M, Räty R, Andersen NS, et al. Nordic MCL2 trial update: six-year follow-up after intensive immunochemotherapy for untreated mantle cell lymphoma followed by BEAM or BEAC + autologous stem-cell support: still very long survival but late relapses do occur. Br J Haematol. 2012;158:355-62. https://doi.org/10. 1111/j.1365-2141.2012.09174.x.

35. Nordström L, Sernbo S, Eden P, Grønbæk K, Kolstad A, Räty R, et al. SOX11 and TP53 add prognostic information to MIPI in a homogenously treated cohort of mantle cell lymphoma - a Nordic lymphoma group study. Br J Haematol. 2014;166:98-108.

36. Husby S, Ralfkiaer U, Garde C, Zandi R, Ek S, Kolstad A, et al. miR-18b overexpression identifies mantle cell lymphoma patients with poor outcome and improves the MIPI-B prognosticator. Blood. 2015;125:2669-77.

37. Hoster E, Rosenwald A, Berger F, Bernd H-W, Hartmann S, Loddenkemper C, et al. Prognostic value of Ki-67 index, cytology, and growth pattern in mantle-cell lymphoma: results from randomized trials of the European mantle cell lymphoma network. J Clin Oncol. 2016;34:1386-94. https://doi. org/10.1200/JCO.2015.63.8387.

38. Chihara D, Asano N, Ohmachi K, Kinoshita T, Okamoto M, Maeda Y, et al. Prognostic model for mantle cell lymphoma in the rituximab era: a nationwide study in Japan. Br J Haematol. 2015;170:657-68. https://doi.org/ 10.1111/bjh.13486.

39. Ferrero S, Rossi D, Rinaldi A, Bruscaggin A, Spina V, Eskelund CW, et al. KMT2D mutations and TP53 disruptions are poor prognostic biomarkers in mantle cell lymphoma receiving high-dose therapy: a FlL study. Haematologica. 2020;105:1604-12.

40. Wang Y, Ma S. Risk factors for etiology and prognosis of mantle cell lymphoma. Expert Rev Hematol. 2014;7:233-43.

41. Elhassadi E. Is TP53 mutation screening in mantle cell lymphoma (MCL) ready for prime time? Ann Clin Oncol. 2019;2019:1-4.

42. Sonbol MB, Maurer MJ, Stenson MJ, Allmer C, Laplant BR, Weiner GJ, et al. Elevated soluble IL-2Ra, IL-8, and MIP-1B levels are associated with inferior outcome and are independent of MIPI score in patients with mantle cell lymphoma. Am J Hematol. 2014;89:E223-7.

43. Ek S, Björck E, Högerkorp C-M, Nordenskjöld M, Porwit-MacDonald A, Borrebaeck CAK. Mantle cell lymphomas acquire increased expression of CCL4, CCL5 and 4-1BB-L implicated in cell survival. Int J Cancer. 2006;118: 2092-7. https://doi.org/10.1002/ijc.21579.

44. Planken EV, Dijkstra NH, Willemze R, Kluin-Nelemans JC. Proliferation of B cell malignancies in all stages of differentiation upon stimulation in the "CD40 system". Leukemia. 1996;10:488-93 http://www.ncbi.nlm.nih.gov/ pubmed/8642867. Accessed 23 Mar 2020.

45. Visser HPJ, Tewis M, Willemze R, Kluin-Nelemans JC. Mantle cell lymphoma proliferates upon IL-10 in the CD40 system. Leukemia. 2000;14:1483-9. https://doi.org/10.1038/sj.leu.2401829.

46. Castillo R, Mascarenhas J, Telford W, Chadburn A, Friedman SM, Schattner EJ. Proliferative response of mantle cell lymphoma cells stimulated by CD40 ligation and IL-4. Leukemia. 2000;14:292-8.

47. Jin Z, Teramoto N, Hayashi K, Liu YX, Jin G, Oka T, et al. CD40 Ligand Stimulation Inhibits the Proliferation of Mantle Cell Lymphoma Lines. Anticancer Res. 2004;24(2 B):691-7.

48. Nakaki F, Saitou M. PRDM14: a unique regulator for pluripotency and epigenetic reprogramming. Trends Biochem Sci. 2014;39:289-98.

49. Lu Y, Wan Z, Zhang X, Zhong X, Rui L, Li Z. PRDM14 inhibits 293T cell proliferation by influencing the G1/S phase transition. Gene. 2016;595:180-6. https://doi.org/10.1016/j.gene.2016.09.039.

50. Taniguchi H, Imai K. PRDM14, a zinc finger protein, regulates cancer stemness. In: Methods in Molecular Biology: Humana Press Inc.; 2018. p. 313. https://doi.org/10.1007/978-1-4939-8799-3_1.

51. Zhang T, Meng L, Dong W, Shen H, Zhang S, Liu Q, Du J. High expression of PRDM14 correlates with cell differentiation and is a novel prognostic marker in resected non-small cell lung cancer. Med Oncol. 2013;30(3):605.

52. Taniguchi H, Hoshino D, Moriya C, Zembutsu H, Nishiyama N, Yamamoto H, et al. Silencing PRDM14 expression by an innovative RNAi therapy inhibits stemness, tumorigenicity, and metastasis of breast cancer. Oncotarget. 2017; 8:46856-74. https://doi.org/10.18632/oncotarget.16776.

53. Ou M, Li S, Tang L. PRDM14: a potential target for Cancer therapy. Curr Cancer Drug Targets. 2018;18:945-56. https://doi.org/10.2174/ 1568009618666180430143055 . 
54. Nishikawa N, Toyota M, Suzuki H, Honma T, Fujikane T, Ohmura T, et al. Gene amplification and overexpression of PRDM14 in breast cancers. Cancer Res. 2007;67:9649-57.

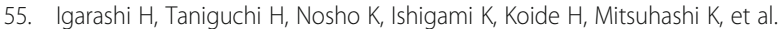
PRDM14 promotes malignant phenotype and correlates with poor prognosis in colorectal cancer. Clin Transl Oncol. 2019:1-12.

56. Tracey $L$, Justice MJ. Off to a bad start: Cancer initiation by Pluripotency regulator PRDM14. Trends Genet. 2019;35:489-500. https://doi.org/10.1016/j. tig.2019.04.004.

57. Dettman EJ, Justice MJ. The zinc finger SET domain gene Prdm14 is overexpressed in lymphoblastic lymphomas with retroviral insertions at Evi32. PLoS One. 2008;3:e3823.

58. Tam W, Gomez M, Chadburn A, Lee JW, Chan WC, Knowles DM. Mutational analysis of PRDM1 indicates a tumor-suppressor role in diffuse large B-cell lymphomas. Blood. 2006:107:4090-100.

59. Zhang XY, Ma ZP, Cui WL, Pang XL, Chen R, Wang L, et al. Impact of PRDM1 gene inactivation on C-MYC regulation in diffuse large B-cell lymphoma. Zhonghua bing li xue za zhi. 2018;47:25-31.

60. Zhang XY, Ma ZP, Cui WL, Chen R, Glinaer A, Miao N, et al. Potential mechanism and prognostic value of promoter methylation of PRDM1 gene in diffuse large B cell lymphoma. Zhonghua bing li xue za zhi. 2016;45:8317. https://doi.org/10.3760/cma.j.issn.0529-5807.2016.12.004.

61. Vose JM. Mantle cell lymphoma: 2017 update on diagnosis, risk-stratification, and clinical management. Am J Hematol. 2017;92:806-13. https://doi.org/10. 1002/ajh.24797.

\section{Publisher's Note}

Springer Nature remains neutral with regard to jurisdictional claims in published maps and institutional affiliations.

Ready to submit your research? Choose BMC and benefit from:

- fast, convenient online submission

- thorough peer review by experienced researchers in your field

- rapid publication on acceptance

- support for research data, including large and complex data types

- gold Open Access which fosters wider collaboration and increased citations

- maximum visibility for your research: over $100 \mathrm{M}$ website views per year

At BMC, research is always in progress.

Learn more biomedcentral.com/submissions 